\title{
Educação Científica contra o Preconceito: da Natureza às Multinaturezas
}

\author{
Vitor Fabrício Machado Souza ${ }^{\text {(D) }}$ Cristiane Coppe
}

\section{Resumo}

Este artigo traz um recorte da pesquisa de doutorado em Educação Científica, no qual se buscou construir um conjunto de práticas que subsidiem o combate ao preconceito racial em aulas de ciências. Tais pontos são resultado de um movimento de diálogo entre o levantamento de experiências de etnias, aldeias e escolas indígenas, movimentos de educação antirracista e pedagogias decoloniais, além de estudo bibliográfico acerca da temática. $\mathrm{O}$ artigo tem como principal discussão teórica a decolonialidade do currículo, alicerçando aspectos que vão desde a consciência da existência do preconceito nos indivíduos e na sociedade; passam pelo combate contra a discriminação; por uma auto-socio-crítica do mundo moderno atual; e chegam até as novas proposições, reinvenções e reativações de práticas e conhecimentos originários. Resultam deste processo 36 pontos a serem observados e discutidos por professores e professoras de Ciências Naturais a fim de combater e minimizar preconceitos em sala de aula. Sob estas perspectivas, atuar contra o preconceito e a discriminação em sala de aula tem como máxima "desaprender para aprender", praticada em perspectivas individuais e sociais. O estudo também favoreceu a percepção indispensável de revisão sobre o papel e o significado da natureza, à luz de saberes e proposituras educacionais decoloniais.

\section{Palavras-chave PRECONCEITO • POVOS INDÍGENAS • CIÊNCIAS DA NATUREZA • ENSINO DE CIÊNCIAS}

\section{Science Education against Prejudice: from Nature to Multinatures}

\begin{abstract}
This article presents an excerpt of a doctoral research in Science Education in which we sought to build a set of practices that support the fight against racial prejudice in science classes. This is the result of a movement of interaction between surveys on experiences of ethnic groups, villages and indigenous schools; movements of anti-racist education and decolonial pedagogies, in addition to a bibliographic study on the notion of multinatures. The main theoretical discussion of the article is about decolonizing the curriculum, supporting aspects that range from the awareness of the existence of prejudice in individuals and the society, go through the fight against discrimination, self and social criticism of the modern world, until new propositions, reinventions and reactivations of original practices and knowledge. This process resulted in 36 points to be observed and discussed by teachers of Natural Sciences in order to combat and minimize prejudice in the classroom. From these perspectives, acting against prejudice and discrimination in the classroom has as a maxim the principle of "unlearning to learn", practiced in individual and social perspectives. The study also favored the indispensable perception of reviewing the role and meaning of nature, in light of a decolonial educational praxis.
\end{abstract}

Keywords PREJUDICE • INDIGENOUS PEOPLE • NATURAL SCIENCES • SCIENCE TEACHING 


\section{Introdução}

Ao versar sobre a diferença entre preconceito, discriminação e racismo, o filósofo Silvo Almeida (2018) exemplifica que considerar orientais "naturalmente" preparados para as ciências exatas, judeus avarentos ou negros inconfiáveis são exemplos de preconceitos, isto é, um "juízo baseado em estereótipos acerca de indivíduos que pertençam a um determinado grupo" (Almeida, 2018, p. 25). Um preconceito pode ou não se tornar ação, ou seja, gerar práticas discriminatórias que tratam determinadas pessoas de maneira diferenciada, estigmatizando-as. Por sua vez, os "preconceitos estruturais" são formas sistemáticas de discriminação, que tomam como fundamento a raça, o gênero ou a sexualidade. Este tipo de "discriminação tem como requisito fundamental o poder" (Almeida, 2018, p. 25). Portanto, racismo, machismo e homofobia são preconceitos estruturais, pois se manifestam em ações objetivas na estrutura de uma sociedade, discriminando determinadas pessoas. A sociedade, as escolas e as salas de aulas e as aulas de ciências são espaços que convivem com preconceitos, discriminações e preconceitos estruturais. Para nós, combater os preconceitos, as discriminações é um compromisso ético que extrapola todo e qualquer lugar ou contexto.

Para uma ciência, uma aula, uma disciplina ou uma professora ou professor em sala de aula poder combater os preconceitos dentro dela não é preciso que alguma lei o impinja. Ao contrário, a própria emergência de um estado como forma de engendrar a socialidade das pessoas se deu a partir das invasões dos territórios americanos e das violências cometidas contra os povos indígenas, africanos e as mulheres (Mignolo, 2017) ${ }^{1}$. Silvia Federici (2019) mostra como a transição para o capitalismo necessitou da mão de obra e de corpos reprodutivos das mulheres na Europa. Enquanto nas terras invadidas, as vantagens comparativas criadas pelos invasores fizeram emergir formas de dominação, opressão e controle de diversos povos e populações (Wahren, 2015). Os preconceitos estruturais da nossa sociedade - racismo, machismo e homofobia - têm origem ou são asseverados na colonialidade que funda os estados-nação (Mignolo, 2017). Por isso, quando utilizamos o termo "combate ao preconceito" neste trabalho, estamos falando das suas manifestações possíveis, sejam elas estruturais ou não, discriminatórias ou não. O caminho sobre o qual esta discussão se ergueu foi o do preconceito, discriminação e racismo contra povos indígenas. O Brasil, enquanto estado-nação, abriga dentro de suas fronteiras 252 povos, 154 línguas diferentes, 705 terras e mais de 700 mil pessoas que se declaram indígenas (Ricardo \& Ricardo, 2017). Em sua Constituição de 1988, o Brasil garante aos "índios" o reconhecimento de sua "organização social, costumes, línguas, crenças e tradições, e os direitos originários sobre as terras que tradicionalmente ocupam, competindo à União demarcá-las, proteger e fazer respeitar todos os seus bens"

1 Como se verá no texto, a colonialidade do saber defendida, entre outros, por Walter Mignolo (2017), se manifesta ainda hoje na própria língua que diferencia termos e situações com especificidades, como "América" e "América Latina". Mas também na nomenclatura de nomes próprios de instituições. Por esta razão, optamos por grafar termos como "estado", "europa", "américa", "ocidente" e "ciência" com iniciais minúsculas, salvo quando representam nomes de áreas disciplinares escolares. 
(Constituição da República Federativa do Brasil, 1988, p. 133)². E, no artigo 210 deste mesmo documento, assegura-se às comunidades indígenas o ensino de suas línguas nativas, respeitando os processos próprios de aprendizagem dessas comunidades. Isso se fortalece e se especifica na Lei de Diretrizes e Bases da Educação Nacional, na qual são garantidos os direitos à reafirmação de suas identidades étnicas, ao fortalecimento de práticas culturais, currículos, programas e materiais didáticos específicos (Lei de Diretrizes e Bases da Educação Nacional, 1996).

Ademais, em 2004, o Brasil se tornou signatário da Convenção 169 da Organização Internacional do Trabalho Sobre Povos Indígenas e Tribais, 15 anos após a sua elaboração, em 1989. E esse documento preconiza que é dever do estado não apenas garantir a participação dos povos indígenas nas decisões que dizem respeito às suas práticas e territórios, mas, sobretudo, também adotar medidas de caráter educativo em todos os setores da comunidade nacional, "com o objetivo de se eliminar os preconceitos que poderiam ter com relação a esses povos” (OIT, 1989). Ou seja, é preciso educar a população brasileira para respeitar os povos indígenas e suas formas de viver. A lei 11.645/08 torna obrigatório, para todo o currículo escolar, "nos estabelecimentos de ensino fundamental e de ensino médio, públicos e privados, o estudo da história e cultura afro-brasileira e indígena" (Lei 11.645, de 10 de março de 2008)

Contudo, o próprio texto dessa lei permite que as instituições formuladoras de políticas públicas educacionais interpretem como obrigatório o estudo da história e cultura indígenas apenas para as disciplinas de História, Artes e Língua Portuguesa: afirma que esses conteúdos serão "ministrados no âmbito de todo o currículo escolar, em especial nas áreas de educação artística e de literatura e história brasileiras [ênfase no original]" (Lei 11.645, de 10 de março de 2008). Um exemplo de que essa falta de clareza tem consequências práticas está na formulação dos editais do Plano Nacional do Livro Didático (PNLD). No edital de 2015, para distribuição das obras para o ensino médio entre 2018 e 2020, consta que será bem avaliada a coleção que "promover positivamente a cultura e história afro-brasileira e dos povos indígenas brasileiros, dando visibilidade aos seus valores, tradições, organizações, conhecimentos [...]" (Ministério da Educação, 2015, p. 32). Contudo, apenas a disciplina de história tem um item explícito de exclusão da coleção que não "desenvolve abordagens qualificadas sobre a história e cultura da África, dos afrodescendentes, dos povos afro-brasileiros e indígenas [...]" (Ministério da Educação, 2015, p. 47). Ou seja, na prática, a obrigatoriedade foi válida apenas para História, pois todas as outras disciplinas apenas serão bem avaliadas caso tratem de conhecimentos indígenas. Nos editais para elaboração e distribuição de livros didáticos, por exemplo (Ministério da Educação, 2019), não há a obrigatoriedade de trabalhar a cultura e os conhecimentos científicos afro-brasileiros e indígenas.

Ao contrário, nos livros didáticos, a visão acerca dos conhecimentos indígenas é, geralmente, deturpada e estereotipada (Oliveira, 2003). Apesar de já existirem áreas

2 O texto original da constituição utiliza o termo "índios". Contudo, como defende o movimento indígena atualmente, a palavra "índio" é carregada de preconceito, devendo, portanto, ser evitada. Neste sentido, ao utilizála conforme a fonte original, grafamos entre aspas. 
de pesquisa como etnomatemática, etnociência ou etnobotânica, por exemplo, não necessariamente o foco dos trabalhos destas áreas é o preconceito contra os povos por meio dos quais aqueles conhecimentos emergem. No Brasil, quando se analisam as pesquisas contra os preconceitos e os povos indígenas em aulas de ciência, pouco se verifica.

Neste artigo trataremos das ciências indígenas e suas multinaturezas, defendendo que é papel também das disciplinas que compõem a área de Ciências da Natureza e suas Tecnologias fomentar conhecimentos referentes a povos indígenas e afro-brasileiros na escola básica, assim como combater o preconceito em sala de aula. Oferecemos ainda um esquema de reflexão e ação baseado nesses conhecimentos tradicionais e em pesquisas sobre o tema, que podem permitir às pessoas desaprender os preconceitos impostos pela colonialidade, além de aprender novas práticas, saberes e ciências obliterados pela ontologia ocidental. Com isso, esperamos contribuir para o debate e para a construção de um conjunto de práticas preocupadas com a pluralidade de conhecimentos e com o combate ao preconceito na ciência e no seu ensino. É possível e desejável empreender esse processo de desaprender para aprender nas aulas de ciências, nas escolas básicas, nas universidades e nos ambientes acadêmicos de produção de conhecimento, alterando inclusive as suas fórmulas procedimentais. Tal defesa se ancora no imperativo de combate ao preconceito em que nos encontramos agora, mas também no fato de serem os fenômenos naturais significados dentro das ontologias distintas de pensamento ameríndio, meios pelos quais também se torna possível estabelecer diálogos entre perspectivas diferentes de mundo, saldando - e saudando - a diferença dessas perspectivas, das múltiplas ciências indígenas e de sua ligação agenciada com as coisas do mundo (Viveiros de Castro, 2015, p. 42).

Nas seções seguintes, elucidamos o que chamamos de colonialidade, multinaturezas, ontologias de pensamento e o papel destas ideias para a educação científica.

\section{Da natureza para as multinaturezas}

Professores de Ciências da Natureza e suas Tecnologias acreditam que a natureza seja o quê? Em levantamento com professores do ensino fundamental e médio das escolas públicas no Mato Grosso, Aguinel Lima e Haydée Oliveira (2011) verificaram que aproximadamente $50 \%$ dos professores acreditam que a natureza é tudo aquilo que não sofreu ação de transformação pelo homem: as matas, os animais, os alimentos, entre outros. Os outros 50\% estão, grosso modo, divididos entre uma visão mais generalista, em que "tudo é natureza", e uma visão mais utilitarista, segundo a qual a natureza é a fornecedora de recursos para a vida humana (Lima \& Oliveira, 2011). Mas, e se os professores ou as professoras participantes deste levantamento fossem indígenas em suas escolas nas respectivas aldeias, as respostas seriam as mesmas?

Quando Ailton Krenak diz que a montanha na frente da aldeia Krenak, em Resplendor-MG, tem nome e personalidade (Krenak, 2019, p. 18); quando os Achuar desenvolvem toda uma tecnologia de domesticação e reprodução de mandioca para que 
elas não se vinguem gerando espécies venenosas (Descola, 2006, p. 74); quando Daniel Munduruku diz que a coisa existente, seja "uma pedra, uma árvore, um rio ou um ser humano é possuidora de um espírito que a anima e a mantém viva e nada escapa disso" (Munduruku, 2016, p. 27); ou quando os Wajãpi dizem que as coisas, incluindo o fogo, a cerâmica e as árvores, falam (Ajãreaty Wajãpi, 2017), será que todos esses povos, do Alaska à Terra do Fogo, estão aludindo a uma natureza como esta que a maioria dos professores enxergam? Uma natureza apartada do humano? Sendo estes últimos povos indígenas também ensinantes em suas escolas, essas aulas de ciências partem do mesmo princípio? Se, para os Huni-Kuin, um raio que cai com suas luzes e barulhos é vivo (Lévi-Strauss, 2006, p. 421), deveria ser estudado pela biologia e não pela física?

Antes de mais nada, é preciso saber que a construção do que seja natureza é extremamente precária e nasce apenas para diferenciar o humano do resto das coisas. Levi-Strauss (2004) utiliza a ideia do "cru e o cozido" para mostrar como as noções de natureza nascem em função das noções de humanidade. Ou seja, da forma como pensam os professores da pesquisa supracitada, se algo teve intervenção humana (um alimento cozido, um carro, um livro, uma música), então esse algo pertence à cultura. Em contrapartida, se esse algo surgiu sem interferência humana (um alimento cru, uma montanha, um rio, uma árvore), então esse algo pertence ao universo da natureza. Claro está que esta noção é sobremaneira carente. Afinal, olhando para a fotografia de uma soja transgênica, qual de nós diria se tratar de um objeto da cultura? Ou, olhando a fotografia de uma montanha devorada pela mineração, diríamos se tratar de um objeto da natureza? Ou, ainda mais grave, qual de nós, verificando todas as catástrofes ambientais decorrentes do aquecimento global afirmaria se tratar de um fenômeno natural?

Não existem distinções claras entre natureza e cultura, e, se uma pessoa julga que uma montanha não é um ser vivo, ela parte de uma maneira de conceber a realidade, ou seja, de uma ontologia de mundo, na qual, segundo sua concepção, as montanhas não são vivas. Contudo, esta forma de enxergar o mundo e formar pessoas para enxergálo, isto é, educá-las cientificamente, não é única, tampouco exclusiva. E se, ao julgar a dimensão de natureza de outros povos como inexistente, ou menor, ou fruto de crendice, o nome disso é "preconceito ontológico", conforme explicita Daiara Tukano:

Aos povos originários foram impostos a língua, os costumes e os saberes do colonizador, não é à toa que para argumentar nos cobrem constantemente a validação científica de acordo com o pensamento ocidental como se já não tivéssemos o próprio, e justamente por isso nos ver na necessidade de discutir racismo, preconceito e apropriação cultural nos cansa e irrita tanto (Tukano, 2019, p. 102).

Tais preconceitos, como já anuncia Daiara Tukano, são frutos da colonialidade. A colonialidade é decorrente das invasões europeias e perdura até hoje. Trata-se, outrossim, de um processo extremamente violento de dominação de territórios, de pessoas, da "natureza", de conhecimentos e saberes. Ou seja, a colonização das américas não se traduz apenas em um evento passado que dizimou na ponta da lança ou nas epidemias 
mais de 56 milhões de pessoas. Este número só foi precisado recentemente, quando se demonstrou que tamanha matança resultou irrevogavelmente na alteração do clima global (Koch et al., 2019). Não, a colonialidade apresenta a violência contra as crenças, os conhecimentos, as línguas, os deuses e as naturezas de povos originários (Mignolo, 2017). Quem invade ainda detém em suas mãos todos os parâmetros que constroem as narrativas. O tempo, a história e os tempos históricos são definidos pelos invasores.

Os invasores que por aqui desembarcaram traziam consigo uma formação religiosa que já lhes inculcava a ideia de que é um direito divino, firmado em texto bíblico, no livro do Genesis 1, versículo 26, que a natureza deve servir ao homem, e este deve dominar tudo quanto for natural: "Domine ele sobre os peixes do mar, sobre as aves do céu, sobre os grandes animais de toda a terra e sobre todos os pequenos animais que se movem rente ao chão" (Bíblia de Jerusalém, 2003, p. 2). Tal distinção entre o humano especial e o restante fora dele se mantém até hoje e define os conhecimentos. A separação entre o corpo e o espírito, empreendida por Descartes, e a distinção entre os fenômenos e as coisas em si, por Kant, são marcas da ontologia ocidental, que enxerga o humano como ser especial separado da natureza. Mas todo este processo é fruto de disputas. A potência cartesiana coincide com a derrota dos mouros, a expulsão dos judeus e a expansão atlântica. Mouros, judeus e ameríndios - e, com o tempo, também os escravos e as escravas do continente africano - , todos eles, passaram a configurar, no imaginário ocidental cristão, a diferença (exterioridade) no interior do imaginário (Dussel, 2005).

E até hoje esse imaginário erigido a partir do apagamento do diferente se faz presente dentro dos preconceitos ontológicos nas pessoas (Tukano, 2019). E a própria ciência moderna é um braço dessa colonialidade do saber. Quando a américa foi conquistada, nasceu também o eurocentrismo, que colocou o sistema epistêmico referencial na europa e assim diferenciou o resto. A melhor dominação é aquela que, naturalizada, não aparece como tal (Lander, 2005). O que a invasão da américa produziu de maneira comparativa é a noção de verdade, de valor universal, de estado político, de conhecimento científico e de modelo econômico. Essa ideia de ocidente moderno se mostrou ao resto do mundo. O monopólio e a imposição, à força, de um discurso garantiram para a europa a normatização das leis físicas, morais, políticas, econômicas, éticas e estéticas. Nas palavras de Daniel Munduruku e de Cristino Wapichana:

Desde que o ser humano se colocou acima da natureza e passou a contar a história tendo como referência a si mesmo e deixando os outros seres vivos à margem. As consequências disso estão sendo notadas, diariamente, por meio de teorias equivocadas a respeito dos outros seres humanos que não aceitaram essa visão dominadora e truculenta (Munduruku \& Wapichana, 2019, p. 35).

Foi depois deste processo que o mundo passou por uma guinada antrópica e entrópica. Os centros de poder possuem licença religiosa, moral e política para explorar a natureza e os povos de outros lugares. E, então, em 2020 professores de ciências acreditam que a natureza é este algo exterior daquilo que supostamente somos enquanto 
humanos (Lima \& Oliveira, 2011). E carregam, como identifica Marilyn Strathern, "a natureza como uma precondição da existência que fornece as matérias primas da vida permitindo o controle, a manutenção e a manipulação desta mesma natureza apartada de nós" (Strathern, 2014, p. 50). Para os povos indígenas a natureza, a pachamama na América Latina, está em tudo, e tudo possui agencialidades, humanidade e intenção (Viveiros de Castro, 2001). Não se trata de um mero ponto de vista diferente, de diversos povos, sobre uma realidade material imutável chamada de natureza, mas, efetivamente, é um conjunto de multinaturezas ontologicamente diferentes. E, como existem multinaturezas, existem múltiplas ciências multinaturais. E, se nós, professores de Ciências Naturais, aprendemos e ensinamos tudo o que se relaciona à natureza, então também precisamos compreender e ensinar as multinaturezas, sob o peso de, ao não o fazer, reforçar as estruturas que engendram os preconceitos dentro e fora da escola.

Não nos devemos enganar e pensar que exista apenas o preconceito ontológico de brancos para com os povos indígenas. O racismo, ou seja, a discriminação sistemática contra povos indígenas, é amplamente verificado no Brasil de hoje. Em extenso levantamento, Felipe Milanez, Ailton Krenak, Lucia Sá e outros pensadores e pensadoras indígenas mostram como o racismo contra povos indígenas está presente no discurso político, na opinião pública, nas instituições (Milanez et al., 2019). Imagens de indígenas como selvagens, canibais, sujos e preguiçosos são frequentemente encontradas pelo Brasil afora, denotando o profundo racismo que precisa ser combatido (Lima et al., 2016). Tais preconceitos datam precisamente da invasão e da colonização das américas. Por isso, é preciso que descolonizemos os saberes e as ciências, para também combater o racismo contra povos indígenas.

Integramos neste trabalho aquilo que se convencionou chamar de pensamento decolonial, isto é, um modo de encarar o mundo, as ciências e a história a partir dos adventos seguidos da colonização de territórios e a partir dos territórios colonizados. A postura decolonial é tão antiga quanto a colonização e emerge no primeiro segundo em que os povos indígenas se rebelaram contra os invasores. Com isso, esperamos deseducar os preconceitos ontológicos e raciais que pululam entre as pessoas. E, se alguém aprendeu a ser preconceituoso - "Nenhuma criança nasce preconceituosa. Ela aprende a sê-lo" (Gomes, 2005) —, também poderá desaprender. Por isso, há uma máxima que precisa sempre "sulear" ${ }^{3}$ os horizontes, quando se trata de combater o preconceito: desaprender para aprender. Ou, como elucida Daniel Munduruku e Cristino Wapichana, ao lembrarem que "a consciência pode ser educada, transformada e utilizar o apreendido para transformar as relações através do uso correto das palavras" (Munduruku \& Wapichana 2019, p. 14).

Na próxima seção, mostraremos quais lições e ensinamentos dos povos indígenas os movimentos decoloniais e antirracistas têm para nos apontar caminhos contra o preconceito em sala de aula.

3 Afinal, o "nortear" só é sinônimo de "orientação correta", por decisão colonial. Tanto os barcos invasores quanto as linhas de campo magnético saem do norte e vão para o sul, não sem coincidência. 


\section{Construindo pilares e princípios}

A terra indígena Araribá, onde hoje é o município de Avaí, no interior do estado de São Paulo, abriga quatro aldeias: Kopenoti e Ekeruá, de povos da etnia Terena; e as Nimuendaju e Tereguá, de povos Guarani Ñandewa. Juntas, suas escolas indígenas produziram uma cartilha para que as pessoas não indígenas, sobretudo as que visitam uma ou outra aldeia, possam aprender - talvez - a deixar de ser preconceituosas (Cury, 2017, pp. 46-47). Apesar da obviedade das questões, leem-se nessa cartilha da Figura 1 alguns aspectos:

Figura 1. Cartilha Terena contra o preconceito, para quebrar estereótipos sobre os povos indígenas QUEBRANDO ESTEREÓTIPOS

\begin{abstract}
Atualmente um dos grandes desafios para a sociedade brasigenas. Muitas relações $\ominus$ stabelecidas com esses povos săo pautadas por desrespeito, preconceito $\theta$ dificuldade de entender o outro. Abaixo seguem algumas dicas para você.
\end{abstract}

Os índios nāo sāo todos iguais

Hoje no Brasil existem mais de 250 povos indígenas, 180 línguas sendo faladas. No entanto, os não indígenas continuam achando que todos são Tupi-Guarani. Muitas vezes nem nossos vizinhos sabem que existe uma aldeia na sua cidade.

\section{Moradia}

Antigamente os indígenas moravam em casas tradicionais, fөitas de madeira, sapé, cipó $\theta$ bambu. Naquele tempo havia muitos recursos naturais $\theta$ hoje năo existem mais, devido aos desmatamentos que ocorreram. Por isso, os indígenas moram em casas $d \ominus$ alvenaria $\theta d \theta$ outros materiais.

Os indígenas podem viver $\theta \mathrm{m}$ casas tradicionais, depende da regiăo onde se encontram. O morar em ocas requer uso de matérias-primas coletadas na natureza, porém nem toda região do Brasil ainda tem florestas ou matas. Atualmente é possível encontrar essa moradia somente em certas regiões brasileiras.

\begin{abstract}
Vestimenta
Os indigenas năo andam nus, porque hoje as aproximaçõ com a sociedade dominante são constantes, praticamente todos os dias. Mas não somente por isso que os indígenas não andam mais nus. As intempéries também contribuem para que os indígenas usem roupas não indígenas.
\end{abstract}

\begin{abstract}
Transporte
Hoje em dia os indígenas têm carros, motos, tratores $\theta$ outros veículos, porque eles precisam ir para cidade comprar alimentos, estudar, trabalhar $\theta$ fazer outras atividades. Antigamente utilizavam canoas, cavalos $\theta$ andavam também a pé. Porém os tempos mudaram $\theta$ os indígenas possuem necessidades de locomoção como qualquer pessoa.
\end{abstract}

\begin{abstract}
Tecnologia
As pessoas continuam achando que os indígenas se comunicam através de sinal de fumaça, mas isso não é verdade! Hoje os indígenas $s \theta$ comunicam com outras comunidades $\theta$ seus parentes através de celulares, computadores $\theta$ outros meios de comunicação. No entanto, não deixam deser indígenas $\theta$ nem deixam de praticar suas culturas tradicionais. A tecnologia $\theta$ o acesso à internet atualmente são $\theta s s e n-$ ciais para a comunicação $\theta$ o conhecimento, assim muitos povos passaram a utilizar tais instrumentos para cada $v \ominus z$ mais melhorar o modo de vida da sua comunidade.
\end{abstract}

Fonte: retirado de Cury, 2017.

Pode parecer um texto mais infantil, para crianças, mas, mesmo entre adultos não indígenas, há um desconhecimento sobre estas questões, o que faz com que a educação contra o preconceito precise ir, inclusive, além da escola, embora ela seja, sem dúvida, o espaço principal a partir do qual é possível algum tipo de reeducação contra tais 
preconceitos. Os povos indígenas estão há mais de cinco séculos alertando os brancos "como crianças", dado que estes agem sem saber a consequência de suas ações, sem conhecer as coisas que precisam ser mudadas e educadas.

A mais enfática trivialidade esquecida nos currículos e nas diretrizes educacionais do Brasil é que "educação é para sobreviver" (Mato Grosso, 1997) e para engendrar a sobrevivência além de nós. Não somente ela, pois todos os conhecimentos que dentro dela se mobilizam devem estar voltados para a qualidade de vida, dirão os Wherá (Santa Catarina, 1998). E os Pataxós expressam como este princípio de vitalidade se traduz nas suas escolas indígenas, ao entoar: "como movimento da nossa vida na Terra, vamos usar a força da lente do nosso olhar, da nossa mente, da nossa audição para fortalecer a nossa cultura, nossa educação e a cura da nossa terra" (Pataxó da Aldeia Muã Mimatxi (Povo), 2012 , p. 6). Curar a terra é também curar a Terra. Entretanto, sobretudo nas escolas não indígenas, nas aulas de Ciências, esquece-se de mostrar que esta Terra está doente. A educação indígena está nos mostrando novamente que "a educação respeita a natureza, ensina o que é vida, o que é ruim, o que é bom. Ensina da terra, da água, da natureza" (Mato Grosso, 1997). Educar tem quatro princípios básicos para os Munduruku: (1) Terra como mãe; (2) Ser humano, mesmo caminho; (3) O mundo tem alma; (4) Gratidão à mãe Terra.

Educar é para a formação da consciência a favor da vida, da paz no campo e na cidade, da harmonia entre os povos. Para a compreensão e a colaboração e não para a disputa do saber; não para a competição e sim para a paz (Munduruku, 2016 p. 70).

Tais apontamentos indicam para professores de Ciências, no mínimo, um caminho de escolha para descortinar a mutação climática em curso e todas as catástrofes ambientais que se apresentam hoje ao globo. Mas, para além disso, uma nova relação com a natureza, com o educar e com a pluralidade é um apelo contra os preconceitos e estereótipos sobre os povos indígenas. Os Maxakali nos lembram que "a escola comum, do homem branco, não é adequada ao próprio branco. [...] tem se tornado uma experiência, em geral, enfadonha para nossas crianças e para nós, professores. Tudo aí se traduz em fichas de controle, disciplinamento, segmentação, sentenças" (Campos, 1998, p. 72). A escola, devemos ponderar, é a corporificação do projeto da modernidade. Carregam todas, portanto, os seus predicados exclusivos e excludentes, como aponta Silva (1995, p. 245):

A escola corporifica as ideias de progresso constante através da razão e da ciência, de crença nas potencialidades do desenvolvimento de um sujeito autônomo e livre, de universalismo, de emancipação e libertação política e social, de autonomia e liberdade, de ampliação do espaço público através da cidadania, de nivelamento de privilégios hereditários, de mobilidade social. A escola está no centro dos ideais de justiça, igualdade e distributividade do projeto moderno de sociedade 
e política. Ela não apenas resume esses princípios, propósitos e impulsos; ela é a instituição encarregada de transmiti-las, de torná-los generalizados, de fazer com que se tornem parte do senso comum e da sensibilidade popular. A escola pública se confunde, assim, com o próprio projeto da modernidade. É a instituição moderna por excelência.

E a modernidade, sabemos, engendrou e engendra os preconceitos estruturais de nossa sociedade. Assim a escola, como apontam desde muito tempo as lutas antirracistas, infelizmente colabora para perpetuar preconceitos e reproduzi-los: "Historicamente, o sistema de ensino brasileiro pregou, e ainda prega, uma educação formal de embranquecimento cultural em sentido amplo" (Santos, 2005, p. 22). A escola moderna ocidental, "em busca de uma suposta igualdade, tem padronizado e homogeneizado sua experiência, tendo como referência um único grupo social: o grupo que detém o poder" (Leite, 1998, p. 77). Portanto, é preciso descolonizar também a escola. Fomentar novas práticas, novas epistemes e novas naturezas.

Uma forma de pensar e de agir é colocar-se em oposição às formas hegemônicas através das quais os conhecimentos - em especial o científico - se estabeleceram e considerar efetivamente os conhecimentos historicamente obliterados pelo processo colonial. Trata-se, com efeito, de uma desobediência epistêmica, que aponta para táticas, sujeitos, conhecimentos e instituições descoloniais (Mignolo, 2017). Isabelle Stengers invoca o termo to reclaim para defender uma "reativação" dos conhecimentos nativos e negados pela metrópole (Stutzman, 2018). "Reativar" diz respeito não a um gesto nostálgico de repetição do passado, mas a ações e práticas situadas pelo empirismo e pelo pragmatismo (Stengers, 2018). Edgardo Lander (2005) enumera seis práticas alternativas ao pensamento eurocêntrico-colonial para serem levadas adiante, sobretudo na educação das pessoas desde a América Latina:

1) uma "episteme da relação" baseada na participação coletiva e no saber popular; 2) a práxis no lugar da teoria pode libertar a canonização que há das formas de aprender-construir-ser no mundo; 3) o reconhecimento do sujeitoobjeto na pesquisa e não apenas do objeto; 4) o reconhecimento da pluralidade epistêmica, de que existem outras formas de conhecimento e formas de conhecer e que o conhecimento é sempre histórico, indeterminado, indefinido, inacabado e relativo; 5) o reconhecimento e a resistência dos modos alternativos de fazer-conhecer; 6) a revisão de métodos, as contribuições e as transformações provocadas por eles (Lander, 2005, p. 15).

Estas premissas para descolonizar os saberes se traduzem em sala de aula nas chamadas "pedagogias decoloniais"; isto é, ações organizadas, analíticas e psíquicas que visam a rupturas, transgressões e inversões de práticas impostas e herdadas (Walsh, 2013). Contra a noção de teoria e o empirismo objetivista das ciências modernas, Stengers (2018) propõe "receitas feiticeiras", fundadas na experimentação ativa, abertas ao imponderável e ao imprevisível. Em síntese, as práticas decoloniais na escola consistem 
em: (1) desobediência epistêmica contra as formas hegemônicas de conhecimento; (2) valorização dos conhecimentos práticos, populares e dos povos originários, assim como os processos investigativos dos quais esses conhecimentos erigem; (3) conhecimentos voltados para qualidade de vida, respeitando a natureza e sua vida; e (4) reconhecimento da pluralidade de modos de conhecimento.

Em sentido mais amplo, é possível, com segurança, afirmar que as pedagogias decoloniais propostas não se centram especificamente em uma pauta antirracista específica, mas voltam-se à refundação dos conhecimentos e práticas à luz de referenciais anti-hegemônicos. Desse modo, a luta decolonial é também contra os preconceitos estruturais erigidos pela modernidade. E, embora tenhamos abordado até agora o preconceito contra indígenas, nesta perspectiva, as pedagogias decoloniais operam contra todas as formas de preconceito baseadas na colonialidade - portanto, do patriarcado branco. Ações decoloniais são também formas de combate ao racismo, à misoginia, ao machismo, ao sexismo e à LGBTQIA+fobia. Por isso a importância de refundar as bases por meio das quais pensamos o conhecimento científico e seus métodos.

Quando se trata em específico da luta antirracista, a bibliografia se estende de ensinamentos urgentes para a educação científica. Em especial, Eliane Cavalleiro (2005) descortina as maneiras pelas quais professores e estudantes de escolas públicas agem quando se trata de racismo, a forma como o entendem e, sobretudo, quando acreditam que vivenciaram ou não atos racistas. Mostra a autora, em extenso trabalho, que os professores, na maioria das vezes, não percebem a existência do racismo ou dos atos discriminatórios na escola. E isso faz com que nenhum tipo de ação seja implementado. Preocupado com as aulas de Ciências e inspirado nesse trabalho, Wilmo Francisco Junior propõe alguns tópicos a serem considerados por professores e professoras de ciências, com vistas a uma educação antirracista:

- Reconhecer a existência do problema racial na sociedade brasileira;

- Buscar, permanentemente, a reflexão sobre o racismo na escola e na sociedade;

- Não conceber qualquer manifestação de preconceito ou discriminação e cuidar para que as relações interpessoais sejam respeitosas;

- Considerar a diversidade presente no ambiente escolar e utilizá-la como forma integradora, encorajando a participação de todos;

- Fazer uma leitura crítica da História Brasileira, mediante à [sic]qual seja possível mostrar a contribuição de diferentes grupos na construção de nosso país;

- Buscar materiais que contemplem a diversidade cultural e étnico-racial, bem como aspectos da África que auxiliem a construção de um currículo menos etnocêntrico;

- Pensar meios e formas em que a educação contribua para o reconhecimento e valorização da diversidade cultural e étnico-racial brasileira;

- Elaborar ações que propiciem o fortalecimento da identidade e autoestima de educandos pertencentes a grupos discriminados (Francisco Junior, 2008, 
p. 405).

Para finalizar, nesta seção destacamos de quais maneiras os pensadores e as pensadoras indígenas das pedagogias decoloniais e da educação antirracista entendem que ações podem ser feitas na escola. Buscamos, a seguir, recortar estes ensinamentos à luz da educação científica, sem, no entanto, nos prendermos ao recorte disciplinar. Na seção seguinte, julgando ser importante trazer esta discussão ao seio das aulas de Ciências da Natureza e suas Tecnologias, iremos propor um conjunto de ações inspiradas no até agora dito.

\section{Educação científica contra o preconceito}

Entre os anos de 2016 e 2020, em decorrência de trabalho de pesquisa, visitamos de diversas formas povos e aldeias indígenas, para aprender e ouvir suas lideranças, seus professores e professoras, sobretudo de ciências. O escopo geral da pesquisa visava encontrar formas pelas quais as aulas de ciências naturais pudessem contribuir para minimizar o preconceito contra os povos indígenas. Este grande objetivo emergiu após as conversas com professores e professoras indígenas, que destacaram o combate ao preconceito como a maior necessidade para todo o conjunto disciplinar das escolas não indígenas. Pessoalmente visitamos aldeias Vanuíre (das etnias Krenak e Kaingang) e Ekeruá (da etnia Terena) no estado de São Paulo. E, na forma de livros, palavras e falas orais aprendemos também com uma série de outras etnias citadas já aqui. Como parte de uma postura decolonial, em nenhum momento consideramos as falas, as conversas, os textos e as manifestações indígenas como "entrevistas" que podemos analisar e das quais, mediante determinado conjunto metodológico canônico, extrair lições. Ao contrário, sempre consideramos tais saberes e falas como referenciais fundamentais da pesquisa. Neste artigo em específico, procuramos construir um conjunto de práticas que subsidiem o combate ao preconceito em aulas de ciências.

Para realizar este movimento de diálogo - como à roda da fogueira - entre falas indígenas, movimentos antirracistas e a literatura decolonial, não nos ancoramos em algum tipo de metodologia predefinida, mas sim nas junções de saberes cuja finalidade última é comum, embora se mostrem na prática, quando se trata de escolas não indígenas, com sutilezas e especificidades outras. Desse modo, ao reunir no grande círculo três movimentos diferentes, buscamos tomar o princípio "desaprender para aprender" como guia de ações concretas válidas para professores e professoras ${ }^{4}$.

O que propomos a seguir é uma reunião de ações inspiradas nos conhecimentos indígenas, nas pedagogias decoloniais e na educação antirracista para combater o preconceito em aulas de Ciências. A base dessas ações é, reiteramos, o processo de “desaprender para aprender". Isso significa que é possível pensar em ações em sala de aula que possibilitem desaprender ideias e práticas contaminadas pelo preconceito e pela lógica colonial. E não apenas desaprendê-las, mas também aprender novas ideias e práticas cujos impactos se desdobrem na contribuição de uma sociedade mais justa e

4 A ideia de "desaprender para aprender" é de autoria controversa, porém amplamente utilizada nas falas de pessoas do movimento indígena e antirracista. Por isso não citamos nenhum trabalho específico. 
inclusiva (Ministério da Educação, 2018).

Existem aprendizagens e desaprendizagens que pertencem ao campo subjetivo dos indivíduos: uma fala racista em sala de aula é uma ação concreta contra a qual se deve reagir com uma atitude igualmente concreta. Por outro lado, existem aspectos objetivos, presentes nas instituições, no discurso hegemônico e na mídia, que reforçam o preconceito. Contra este "imaginário" preconceituoso, há de implantar-se um novo cenário e uma nova sociedade. Neste movimento destacamos quatro grandes eixos de ação que envolvem: (1) a consciência da existência do preconceito nos indivíduos e na sociedade; (2) o combate ao problema; (3) uma auto-socio-crítica do mundo moderno atual; e (4) a invenção, valorização, a reinvenção e a reativação de práticas e conhecimentos.

O processo de desaprender para aprender está sempre ativo. Ao desaprendermos algo, podemos aprender outras coisas; e o contrário também se verifica, embora sem necessidade de comutação. É possível traçar uma analogia deste esquema com um quadro clínico patológico de uma doença - uma moléstia chamada preconceito pode ser "curada" de diferentes maneiras.

A consciência sobre o problema pode ser comparada ao diagnóstico - a elucidação de que existe um mal e a compreensão daquilo que o sustenta. Preconceitos estruturais podem ser manifestados na escola por meio de frases, palavras, valores e pensamentos. Torna-se essencial, portanto, que toda a educação se esforce em mostrar a existência e a origem deste mal. O combate ao problema seria equivalente a uma intervenção tópica para lidar com algo imediato e ter condições de tratá-lo. Diante de uma ação, de uma fala racista, é preciso apontá-la, destacá-la e estabelecer diálogos para a compreensão de todos sobre aquela atitude. A consciência do problema pode criar desconfortos às posições historicamente privilegiadas. A auto-sócio-crítica do mundo moderno atual se relaciona com um prognóstico amplo, complexo, de causas e efeitos. É preciso compreender a história e a natureza da ciência, assim como os processos de colonização do pensamento e as formas pelas quais se manifestam, inclusive, nos conhecimentos científicos. E, por fim, as novas práticas - as novas ações - seriam as transformações e mudanças de hábitos preventivos que permitem que a moléstia seja curada e nunca mais manifestada. A valorização de práticas, identidades, povos e conhecimento precisa acontecer.

Tal analogia não aprofunda; tampouco é autossuficiente para o dimensionamento de ações. Por isso, faz-se necessário detalhar as ações que existem dentro de cada um destes quatro itens.

\section{Consciência da existência do preconceito nos indivíduos e na sociedade}

1. Reconhecer a existência do problema e refletir sobre as formas pelas quais ele se manifesta. Os preconceitos estruturais existem na sociedade, como existem ações discriminatórias, inclusive na ciência. Trata-se, portanto, de trazer à tona estes casos. 
2. Refletir continuamente sobre os preconceitos estruturais na escola e na sociedade. Um ano escolar está repleto de episódios de preconceitos, e não se deve tratar este assunto como apenas um tópico de um projeto escolar, mas ele deve aparecer no planejamento e nos momentos em que emergirem tais problemas.

3. Considerar a diversidade presente no ambiente escolar e utilizá-la para a compreensão da existência dos problemas. A formação colonial brasileira não está no passado ou nos livros de história. É um processo que está acontecendo agora, diariamente.

4. Reconhecer a pluralidade epistêmica e a existência de outras formas de conhecimento e processos de conhecer. As perguntas "quantas línguas existem no Brasil? Quantas religiões?” teriam respostas reveladoras sobre o grau do conhecimento sobre a diversidade de povos, línguas, ciências e modos de viver que (r)existem no território nacional. Se a turma desconhece essa diversidade, é papel, então, de quem leciona trazê-la sempre. Ainda que desconhecendo as particularidades de cada povo, é preciso sempre lembrar a escala da diversidade e a presença dos povos e visões.

\section{Combate ao problema}

5. Não conceber qualquer manifestação de preconceito. Identificar as formas pelas quais ele se manifesta e combatê-lo em todas as possibilidades de sua manifestação, seja semântica, estrutural, estética ou epistemológica. Qualquer tipo de conivência ou silêncio diante de atitudes racistas, machistas e homofóbicas corrobora esses preconceitos. Assim que aparecerem esses casos, é preciso discutir e combater.

6. Pesquisar e produzir conhecimento, considerando não apenas o objeto da pesquisa, mas também os sujeitos dela. Sujeitos são os que fazem ciência. Pessoas com história, desejos, ideologias, defeitos e qualidades. Ao realizar investigações em sala, não se deve isolar esses aspectos no desenrolar das atividades. Fazê-lo é construir uma imagem imaculada e distante da prática científica. Investigações como "a eletricidade afastou ou aproximou as pessoas da sua família?" são possíveis, subjetivas e científicas, sem exclusão.

7. Trazer à tona a resistência dos modos alternativos de conhecimento formas de conhecer. A resistência sempre existiu como resposta à opressão, mas foi sistematicamente obliterada. É preciso jogar luz, então, sobre conteúdos, práticas e ciências de outros povos, para mostrar o quanto eles resistem. É preciso, acima de tudo, acabar com a ideia de que conhecimentos indígenas são menores do que os científicos. E essa defesa não deve ser retórica, mas documentada. 


\section{Auto-sócio-crítica do mundo moderno atual}

8. Antropologia como metodologia de autoanálise. Trazer a leitura de outros povos sobre a sociedade brasileira é uma forma de desmontar perspectivas autocentradas ou supostamente superiores, pois esta sociedade ocidental está permeada de rituais, de barbárie, morte, violência e "primitivismo", ao contrário do que a visão preconceituosa pode supor sobre as sociedades indígenas.

9. Compreender o fim dos mundos em sentido físico e metafísico. A mutação climática é irreversível, e grande parte das tragédias ambientais planetárias o buraco na camada de ozônio, o desflorestamento, a extinção de vertebrados, a acidificação dos oceanos e a degradação da biosfera terrestre - são alguns sintomas físicos desse processo. É preciso compreender esses processos e suas origens antrópicas de um modelo de sociedade baseado no consumo e no individualismo (Krenak, 2019). Mas é importante também lembrar que este não é um mal da humanidade, mas de alguns humanos adeptos deste sistema, enquanto outros, ao contrário, alertam há séculos os primeiros sobre os grandes riscos de o céu desabar no fim (Kopenawa \& Albert, 2015, p.496).

10. Fazer uma leitura crítica da História Brasileira, mediante a qual seja possível mostrar a contribuição de diferentes grupos na construção de nosso país. A história do Brasil, a história da ciência ou a história da ciência no Brasil precisam reafirmar e trabalhar outras versões da história, nas quais a mirada se dá pelos olhos de quem foi apagado.

11. Reposicionar criticamente a ciência, sua história, sua natureza e suas finalidades e os limites da pesquisa diante do fim do mundo. É preciso haver uma nova noção e uma definição de ciência que não excluam as ciências dos povos originários. A discussão sobre o que é ciência e como ela é feita por diferentes povos deve ser realizada a partir de outros mundos e outras naturezas.

\section{Invenção, valorização, reinvenção e reativação de práticas e conhecimentos}

12. Praticar, experimentar e difundir uma "episteme da relação", baseada na participação coletiva e no saber popular, contra uma epistemologia kantiana, que se baseia no "fenômeno". A noção kantiana de fenômeno como representação do real fora de nós parte de um mundo uno, unívoco e uníssono. Outras ciências implicam outras práticas de conhecimento a partir também de outros agentes.

13. A exaltação à finalidade, ao compromisso e ao afeto. Aprender e ensinar não são tarefas exclusivamente cognitivas. Este paradigma já foi superado, e os afetos são vínculos essenciais.

14. Colaborar para a construção de um currículo menos etnocêntrico e que fortaleça identidades e autoestimas de educandos pertencentes a grupos discriminados. O currículo é um corpo vivo, germinado em cada realidade escolar. Mais do 
que atender leis (11.645/08), é preciso que as redes e as escolas repensem seus currículos para valorizar as culturas, as ciências e as práticas dos povos negros e indígenas.

15. Valorizar a diversidade e os conhecimentos indígenas. Uma ciência Krenak é diferente de uma ciência Yanomami. Não se pode falar indistintamente em "ciências indígenas", tampouco genericamente "indígenas", muito menos "índios". A diversidade é um valor a ser praticado, e não apenas falado.

16. Valorizar os conhecimentos práticos e populares e dos povos originários, de bem comum para a coletividade, investigados pela comunidade com finalidade voltada para qualidade de vida. Na imensa maioria dos povos indígenas, as pessoas mais velhas desempenham um papel epistemológico essencial na preservação de conhecimentos (Munduruku, 2016 p. 69). É preciso definitivamente deixar de taxar conhecimentos dos mais velhos como "crendices" e investigar com quais fundamentos eles se apresentam.

17. A práxis no lugar da teoria pode libertar a canonização que há das formas de aprender-construir-ser no mundo. No mundo, ensina-se falando-mostrandofazendo e aprendemos ouvindo-vendo-fazendo (Rezende, 2013). Não se trata de uma coincidência, quando, na maioria dos lugares do mundo, um eletricista ganha menos que um engenheiro elétrico. A valorização da intelecção, em detrimento dos trabalhos manuais, é parte de uma lógica de conhecimento que precisa ser desconstruída. É preciso um esforço para desencaixotar disciplinas e fugir dos reducionismos isolacionistas que tomam teorias sob domínio universal. Não existem "pessoas" e conhecimentos de exatas, biológicas, humanas. Existem pessoas e conhecimentos.

18. A descrição em detrimento da explicação. O pensamento separador de variáveis cria um sistema ideal que foge da complexidade que os sistemas apresentam. Descrever, mais do que explicar, é um modo de se aproximar da realidade, sem se apartar dela. É viver, estar junto, observar e ser observado. Investigações participativas e discricionais junto com a natureza podem ser propostas.

Estes 18 pontos são desdobramentos para inspirações, mais do que proposituras. Possuem o caráter de uma receita provisória que pode ser testada, em cada um de seus itens, à luz de cada realidade. Ainda assim, pensando em uma materialidade mais concreta, propomos o quadro a seguir, no qual estes 18 itens são sintetizados, a partir do princípio "desaprender para aprender". Neste quadro sinótico buscamos responder, para cada um dos itens, "o quê" pode ser desaprendido e também o que pode ser aprendido eventualmente, quando se desaprende algo. E, alternativamente, também. Isto é, ao aprender algo, o que se pode desaprender a partir disso. Portanto, o quadro amplo apresenta 36 pontos que podem ser lidos de maneira aberta para todas as disciplinas, naquilo que seus respectivos professores e professoras julgarem adaptável. Portanto, o quadro na Figura 2 apresenta os pontos para inspirar e gerar reflexões e, talvez, ações. 
Figura 2. Quadro de tópicos a serem aprendidos e desaprendidos, quando se pretende minimizar preconceitos em sala de aula

\begin{tabular}{|c|c|c|}
\hline \multicolumn{3}{|c|}{ Consciência da existência do preconceito nos indivíduos e na sociedade } \\
\hline & Desaprender & Aprender \\
\hline 1 & ... a ideia de que no Brasil não existe preconceito. & $\begin{array}{l}\text {... as origens e as manifestações do preconceito no } \\
\text { Brasil. }\end{array}$ \\
\hline 2 & $\begin{array}{l}\text {... a ideia de que os conhecimentos científicos foram } \\
\text { construídos sem preconceitos. }\end{array}$ & $\begin{array}{l}\text {... os processos violentos que cercam a construção } \\
\text { dos conhecimentos. }\end{array}$ \\
\hline 3 & $\begin{array}{l}\text {... a ideia de que há uma uniformidade social e racial na } \\
\text { escola. }\end{array}$ & $\begin{array}{l}\text {... a diversidade ancestral das pessoas e a presença } \\
\text { indígena e negra nela. }\end{array}$ \\
\hline 4 & $\begin{array}{l}\text {... que existe apenas uma forma de conhecimento } \\
\text { científico. }\end{array}$ & $\begin{array}{l}\text {... as formas de ciência dos povos do globo, assim } \\
\text { como sua efetividade. }\end{array}$ \\
\hline \multicolumn{3}{|c|}{ Combate ao problema } \\
\hline & Desaprender & Aprender \\
\hline 5 & $\begin{array}{l}\text {... que a escola é um lugar para praticar impunemente a } \\
\text { discriminação. }\end{array}$ & $\begin{array}{l}\text {... o que são práticas discriminatórias e quando as } \\
\text { cometemos. }\end{array}$ \\
\hline 6 & ... que o conhecimento é uma ciência apenas objetiva. & $\begin{array}{l}\text {... as formas pelas quais o conhecimento se constrói } \\
\text { com finalidades no seio de sociedades. }\end{array}$ \\
\hline 7 & $\begin{array}{l}\text {... a ideia de que conhecimentos indígenas ficaram no } \\
\text { passado. }\end{array}$ & $\begin{array}{l}\text {... conteúdos, práticas e atuais modos de conhecer } \\
\text { de povos indígenas. }\end{array}$ \\
\hline \multicolumn{3}{|c|}{ Auto-socio-crítica do mundo moderno atual } \\
\hline & Aprender & Desaprender \\
\hline 8 & $\begin{array}{l}\text {... a enxergar o nosso modo de ser com o olhar de outros } \\
\text { povos. }\end{array}$ & $\begin{array}{l}\text {... a encarar as sociedades e seus conhecimentos a } \\
\text { partir de um único olhar. }\end{array}$ \\
\hline 9 & $\begin{array}{l}\text {... o processo de degradação da natureza atual e suas } \\
\text { causas. }\end{array}$ & $\begin{array}{l}\text { ‥ a negar a mutação climática e os impactos do } \\
\text { capitalismo sobre o meio ambiente. }\end{array}$ \\
\hline 10 & ... a história do Brasil desde os povos oprimidos & ... a história eurocêntrica. \\
\hline 11 & $\begin{array}{l}\text {... uma nova concepção de ciência voltada para a } \\
\text { preservação das vidas. }\end{array}$ & $\begin{array}{l}\text {... a versão eurocêntrica da história da ciência (no } \\
\text { singular). }\end{array}$ \\
\hline \multicolumn{3}{|c|}{ Invenção, valorização, reinvenção e reativação de práticas e conhecimentos } \\
\hline & Aprender & Desaprender \\
\hline 12 & $\begin{array}{l}\text {... a fazer ciência a partir das relações entre humanos e } \\
\text { não humanos. }\end{array}$ & $\begin{array}{l}\text {... que exista um método científico infalível, único } \\
\text { com resultados incontestados. }\end{array}$ \\
\hline 13 & $\begin{array}{l}\text {... que o afeto é essencial para se fazer ciência e } \\
\text { conhecimento. }\end{array}$ & $\begin{array}{l}\text {... que a razão e a frieza são predicados de bons } \\
\text { cientistas. }\end{array}$ \\
\hline 14 & $\begin{array}{l}\text {... quem em cada disciplina escolar existem inúmeros } \\
\text { conhecimentos de povos historicamente obliterados. }\end{array}$ & $\begin{array}{l}\text {... que aquilo que o livro ou o site apresenta seja a } \\
\text { versão final, única e definitiva daquele saber. }\end{array}$ \\
\hline 15 & ... a diversidade de ciências indígenas. & ... que "índio é tudo igual". \\
\hline 16 & $\begin{array}{l}\text {... o conteúdo e o valor dos conhecimentos tradicionais e } \\
\text { seus portadores. }\end{array}$ & $\begin{array}{l}\text {... que saberes tradicionais são "superstição", } \\
\text { "bobagem" ou qualquer coisa do tipo. }\end{array}$ \\
\hline 17 & $\begin{array}{l}\text {... a valorizar a prática e o corpo como formas de fazer } \\
\text { conhecimento. }\end{array}$ & $\begin{array}{l}\text {... que a mente e a razão sejam superiores ao corpo } \\
\text { e à ação. }\end{array}$ \\
\hline 18 & ... a descrever relações multinaturais. & $\begin{array}{l}\text {... que a lei e o modelo sejam exemplos do melhor } \\
\text { tipo de conhecimento produzido. }\end{array}$ \\
\hline
\end{tabular}

Fonte: autoria própria.

RBPEC • Revista Brasileira de Pesquisa em Educação em Ciências | Volume 22 | e32489, 1-23 
Salientamos que tal quadro nasce de uma articulação de diferentes atores e atrizes envolvidos no combate aos preconceitos. Isso implica dizer que, enquanto instrumento de reflexão, cabe a cada leitora e cada leitor relacionar suas práticas e referências com o quadro e estabelecer, por si, um outro diálogo. Contudo, a natureza e a redação do quadro se pretendem práticas, isto é, imediatamente ligadas às salas de aulas não indígenas e seus desafios. Assim, por exemplo, trazer para a sala de aula a discussão sobre patentes e tecnologias e saberes originários; casos sobre preconceitos de cientistas contra pessoas que interferiram na autoria de leis e princípios são formas de demonstrar que existem preconceitos nas ciências, e isso também interferiu na própria natureza da ciência. Ademais, não se omitir quando qualquer situação preconceituosa se apresentar na escola, mas também produzir investigações sem "casos ideais", ou contar histórias sobre conhecimentos indígenas anteriores à invasão, que hoje são vistos pela própria ciência moderna como corretos, são formas de combater, pelo confronto, os preconceitos ${ }^{5}$.

É nossa impressão também que qualquer atividade realizada em uma aula de ciências (e em qualquer outra), se for lida sob a luz deste quadro sugerido, pode ser revista em algum ponto. Por isso, mais do que sugerir exemplos concretos de aulas (e temos reunidas várias experiências para publicações futuras), este quadro apresentado no artigo pode ser um instrumento auxiliador para pensar (ou repensar), mas também para planejar novas aulas.

\section{Considerações}

Procuramos, neste artigo, apresentar um levantamento bibliográfico de saberes, ciências e experiências sobre a natureza e as ciências naturais, obliteradas ao longo do tempo. Tais leituras revelam que o mundo físico, historicamente pensado enquanto inanimado, é possuidor de vida e agencialidades. Essa marca de distinção ontológica sobre a forma de conceber a realidade aponta para a necessidade de se compreender a natureza não como espaço único fora do humano, mas como uma multinatureza de diferentes seres, realidades e povos. O levantamento sobre as multinaturezas, as ciências e a educação indígena se articulou com a literatura educacional decolonial e antirracista para inspirar a emergência de quatro grandes eixos de atuação contra o preconceito, que, por sua vez, compõem um conjunto de até 36 pontos a causarem reflexão e se desdobrarem em ações que são pensadas originalmente para as aulas de ciências da natureza e suas tecnologias, mas também podem inspirar outras áreas, já que a própria segmentação do conhecimento é, em si, fruto de um processo de colonização do saber.

Nós, autores, a partir deste quadro de apontamentos, também já desenvolvemos, em sala de aula do ensino básico e superior, experiências concretas que esperamos apresentar em trabalhos futuros, que se desdobrem a partir destes pontos e das experiências docentes. É preciso, desde já, salientar que minimizar preconceitos em sala

\footnotetext{
5 Entre os conhecimentos ancestrais verificados hoje em dia há o caso das marés. Enquanto Galileu defendia, na sua quarta jornada, que as marés eram causadas pela rotação da Terra (Galilei, 2011[1632]), no Brasil, há milhares de anos, tupinambás já sabiam sobre o papel da lua, as fases corretas e as previsões de eclipses, e tal conhecimento era utilizado de forma prática no dia a dia das aldeias (D’abbeville, 1614, p. 320). Outrossim, é inaceitável tratar conhecimentos e povos indígenas com verbos no passado. A voz de indígenas vivos precisa ecoar.
} 
de aula envolve desafios metodológicos que transcendem o tempo escolar. Uma pessoa pode, muitos anos depois de ter vivenciado uma experiência escolar, recobrá-la dentro de uma nova perspectiva que corroborará para que ela minimize preconceitos. De sorte que esses trabalhos em sala de aula precisam mais inspirar do que apresentar resultados objetivos, universais, replicáveis e apartados de quem somos enquanto seres.

Ainda assim, destacamos e reforçamos a necessidade premente do trabalho para professores e professoras de ciências que lidam com preconceitos e, a partir da forma pela qual enxergam e praticam ciência, eventualmente os perpetuam, sem que disso tomem consciência. Outrossim, para além do aspecto colonial da ciência, o preconceito estrutural na sociedade brasileira é uma realidade a ser combatida. Estamos neste projeto atualmente e seguiremos nele.

\section{Agradecimentos}

Os autores agradecem sobejamente à Lidiane Krenak Damaceno, liderança e professora indígena na aldeia Vanuíre (Krenak e Kaingang), que nos recebeu, nos ensinou e nos educou. Agradecemos também ao professor Thomás Haddad, da EACHUSP, que acompanhou e colaborou ativamente com a pesquisa e os trabalhos desde sua origem.

\section{Referências}

Ajãreaty Wajãpi (Wajãpi) (2017). Conversamos com o que a gente cultiva. In B. Ricardo, \& F. Ricardo, Povos indígenas no Brasil: 2011-2016 (pp. 23-25). Instituto Socioambiental (ISA).

Almeida, S. L. de. (2018). O que é racismo estrutural?. Letramento.

Bíblia de Jerusalém. (2003). São Paulo: Paulus.

Campos, R. C. (1998). Não aponte o dedo para aquarinã. In Minas Gerais. SEE/MG, Bay: a educação escolar indígena em Minas Gerais (pp. 71-76). SEE/MG.

Cavalleiro, E. (2005). Discriminação racial e pluralismo nas escolas públicas da cidade de São Paulo. In SECADI/MEC, Educação anti-racista: caminhos abertos pela lei federal $n^{\circ}$ 10.639/03 (pp. 65-104). SECADI/MEC.

Constituição da República Federativa do Brasil de 1988 (1998). http://www.planalto.gov. br/ccivil_03/constituicao/constituicao.htm

Cury, M. X., Guimarães, V. W., Silva, M. A. \& Carneiro, C. G. (Org.) (2017). Kaingang, Guarani Nandewa e Terena - Resistência já! Fortalecimento e união das culturas indígenas. Museu de Arqueologia e Etnologia da Universidade de São Paulo. 
D’Abbeville, C. (1614). Histoire de la mission des pères capucins en l'isle de marignan et terres circonvoisines où est traicté des singularités admirables \&amp, des moeurs merveilleuses des indiens habitants de ce pais. Gallica: Bibliothèque numérique de la bibliothèque nationale de France. De l'impr. De françois huby. https://archive.org/stream/ histoiredelamiss00clau\#page/n3/mode/2up

Descola, O. (2006). As lanças do crepúsculo. Cosac \& Naify.

Dussel, E. (2005). Europa, modernidade e eurocentrismo. In E. Lander (Org.), A colonialidade do saber: eurocentrismo e ciências sociais. Perspectivas latino-americanas (pp. 55-70). Clacso.

Federici, S. (2019). Calibã e a bruxa: mulheres, corpo e acumulação primitiva (Coletivo Sycorax, Trad.). Elefante. (Original publicado em 2005)

Francisco Junior, W. E. (2008). Educação anti-racista: reflexões e contribuições possíveis do ensino de ciências e de alguns pensadores. Ciência e Educação, 14, 397-416. http:// dx.doi.org/10.1590/S1516-73132008000300003

Galilei, G. (2011). Diálogo sobre os dois máximos sistemas do mundo ptolomaico e copernicano (P. R. Mariconda, Trad., Intr. e notas, $3^{a}$ ed.). Editora 34/Associação Filosófica Scientiæ Studia. (Original publicado em 1632)

Gomes, N. L. (2005). Alguns termos e conceitos presentes no debate sobre relações raciais no brasil: uma breve discussão. In SECADI/MEC, Educação anti-racista: caminhos abertos pela lei federal $n^{\circ}$ 10.639/03 (pp. 65-104). SECADI/MEC.

Koch, A., Brierley, C., Maslin M., \& Lewis, S. (2019). Earth system impacts of the European arrival and great dying in the Americas after 1492. Quaternary Science Reviews, 207(1), 13-36. https://doi.org/10.1016/j.quascirev.2018.12.004

Kopenawa, D., \& Albert, B. (2015). A queda do céu: palavras de um xamã Yanomami. Companhia das Letras.

Krenak, A. (2019). Ideias para adiar o fim do mundo. Companhia das Letras.

Lander, E. (Org.). (2005). A colonialidade do saber: eurocentrismo e ciências sociais. perspectivas latino-americanas. Clacso.

Lei no 9.394/96, de 20 de dezembro de 1996. Estabelece as diretrizes e bases da educação nacional. http://www.planalto.gov.br/ccivil_03/leis/19394.htm

Lei 11.645, de 10 de março de 2008. Altera a lei no 9.394, de 20 de dezembro de 1996, modificada pela lei no 10.639 , de 9 de janeiro de 2003, que estabelece as diretrizes e bases da educação nacional, para incluir no currículo oficial da rede de ensino a obrigatoriedade da temática "história e cultura afro-brasileira e indígena". http://www. planalto.gov.br/ccivil_03/_ato2007-2010/2008/lei/111645.htm

Leite, L. H. A. (1998). Aprendendo com a educação indígena. In SEE/MG, Bay: a educação escolar indígena em Minas Gerais (pp. 76-78). SEE/MG. 
Lévi-Strauss, C. (2004). O cru e o cozido: Mitológicas I. Cosac \& Naify.

Lévi-Strauss, C. (2006). O homem nu: Mitológicas IV. Cosac \& Naify.

Lima, A. M., \& Oliveira, H. T. (2011). A (re)construção dos conceitos de natureza, meio ambiente e educação ambiental por professores de duas escolas públicas. Ciência e Educação, 17(2), 321-337. https://doi.org/10.1590/S1516-73132011000200005

Lima, M. E. O., Faro, A., \& Santos, M. dos (2016). A desumanização presente nos estereótipos de índios e ciganos. Psicologia: Teoria e Pesquisa, 32(1), 219-228. https:// doi.org/10.1590/0102-37722016012053219228

Mignolo, W. (2017). Colonialidade: o lado mais escuro da modernidade. Revista Brasileira de Ciências Sociais, 32(94). http://dx.doi.org/10.17666/329402/2017

Ministério da Educação (2015). Edital de convocação para o processo de inscrição e avaliação de obras didáticas para o programa nacional do livro didático PNLD 2015. https://www.fnde.gov.br/index.php/centrais-de-conteudos/publicacoes/category/165editais?download=8304:edital-pnld-2015-ensino-medio-03-07-2013

Milanez, F., Krenak, A., Sá, L., Cruz, F., Ramos, E., \& Taquari, G. (2019). Existência e diferença: o racismo contra os povos indígenas. Revista Direito e Práxis, 10(3), 21612181. https://doi.org/10.1590/2179-8966/2019/43886

Ministério da Educação (2018). Base Nacional Comum Curricular. http:// basenacionalcomum.mec.gov.br/images/BNCC_EI_EF_110518_versaofinal_site.pdf

Ministério da Educação (2019). Edital de convocação no 03/2019 - CGPLI edital de convocação para o processo de inscrição e avaliação de obras didáticas, literárias e recursos digitais para o programa nacional do livro e do material didático PNLD 2021. https://www. fnde.gov.br/index.php/programas/programas-do-livro/consultas/editais-programaslivro/item/13106-edital-pnld-2021

Munduruku, D. (2016). O banquete dos deuses. Global.

Munduruku, D., \& Wapichana, C. (2019). Currículo da cidade: povos indígenas: orientações pedagógicas. SME/COPED.

Oliveira, T. S. de. (2003). Olhares que fazem a "diferença": o índio em livros didáticos e outros artefatos culturais. Revista Brasileira de Educação, (22), 25-34. https://doi. org/10.1590/S1413-24782003000100004

Organização Internacional do Trabalho (OIT) (1989). Convenção 169 da OIT sobre povos indígenas e tribais. Genebra.

Pataxó da aldeia Muã Mimatxi (povo) (2012). Calendários dos tempos. Faculdade de Letras da UFMG.

Rezende, J. S. (2013). Ciências e saberes tradicionais. Tellus, 13(25), 201-213. https://doi. org/10.20435/tellus.v0i25.338 
Ricardo, B., \& Ricardo, F. (2017). Povos indígenas no Brasil: 2011-2016. Instituto Socioambiental (ISA).

Santa Catarina. Secretaria de Estado de Educação (SSEE/SC) (1998). Projeto político pedagógico guarani Wherá. Yynn Moroti Wherá (aldeia M’biguaçú). SEE-SC.

Santos, S. A. (2005). A lei no 10.639/03 como fruto da luta anti-racista do movimento negro brasil. In SECADI/MEC, Educação anti-racista: caminhos abertos pela lei federal $n^{\circ}$ 10.639/03 (pp. 65-104). SECADI/MEC.

Secretaria de Estado de Educação do Mato Grosso (1997). Urucum jenipapo e giz: educação escolar indígena em debate. Entrelinhas.

Silva, T. T. da. (1995). O projeto educacional moderno: identidade terminal? In A. VeigaNeto (Org.), Crítica pós-estruturalista e educação (pp. 245-260). Sulina.

Stengers, I. (2018). The challenge of ontological politics. In M. De La Cadena, \& M. Blaser, A World of many worlds. Duke University Press.

Strathern, M. (2014). O efeito etnográfico. Cosac \& Naify.

Sztutman, R. (2018). Reativar a feitiçaria e outras receitas de resistência: pensando com Isabelle Stengers. Revista do Instituto de Estudos Brasileiros, (69), 338-360. https://doi. org/10.11606/issn.2316-901x.v0i69p338-360

Tukano, D. (2019). Apropriação cultural, antropofagismo, multiculturalidade, globalização, pensamento decolonial e outros carnavais. In O. A. Ribeiro, C. M. Nogueira, R. C. Garcia, \& W. F. Nascimento, Tecendo redes antirracistas, Áfricas, Brasil, Portugal (pp. 99-108). Autêntica.

Viveiros de Castro, E. (2001). A inconstância da alma selvagem. Cosac \& Naif.

Viveiros de Castro, E. (2015). Metafísicas canibais. Cosac \& Naif.

Wahren, J. (2015). Autonomía libertaria, territorios insurgentes y poder popular: Balances y desafíos de las luchas desde abajo y por abajo en la Argentina. In EZLN. El pensamiento crítico frente a la hidra capitalista. (III) (pp. 30-52). Comisión Sexta del EZLN.

Walsh, C. (2013). Lo pedagógico y lo decolonial: Entretejiendo caminos. In C. Walsh (Coord), Pedagogías decoloniales: Prácticas insurgentes de resistir, (re)existir y (re)vivir. Ediciones AbyaYala. 
Vitor Fabrício Machado Souza

Universidade de São Paulo São Paulo, São Paulo, Brasil

vitor.fisica@gmail.com

Cristiane Coppe

Universidade Federal de Uberlândia Ituiutaba, Minas Gerais, Brasil

criscopp@ufu.br

Editor Responsável

Cristiano Barbosa de Moura

Manifestação de Atenção às Boas Práticas Científicas e de Isenção de Interesse

Os autores declaram ter cuidado de aspectos éticos ao longo do desenvolvimento da pesquisa e não ter qualquer interesse concorrente ou relações pessoais que possam ter influenciado o trabalho relatado no texto. 